\title{
Validation of the improved unified constitutive model for open pit applications
}

\author{
A Ford Mining One Pty Ltd, Australia \\ DS Lucas Mining One Pty Ltd, Australia
}

A Vakili Mining One Pty Ltd, Australia

\begin{abstract}
The improved unified constitutive model (IUCM) was developed by collating the most notable recent research works in the area of rock mechanics and extensive back-analysis of mining case histories together into a unified material model. This model has proven to provide a considerably more reliable prediction of rock mass behaviour than other currently available constitutive models. Comparison between IUCM and other conventional models has been shown by Vakili (2017) and Vakili et al. (2014).

Also, a transparent presentation of the model components and a detailed guideline for the selection of input parameters make the IUCM an excellent candidate to potentially become a standard material model for numerical modelling in rock mechanics.

However, as described by Vakili (2016), the majority of the back-analyses and validation studies completed during the development of the IUCM used mining case histories dealing with small to medium underground excavations including development drives/tunnels, vertical shafts, pillars, and open stopes. Therefore, use of the IUCM for other applications such as open pit slope stability required further verification and validation for open pit case histories.

This paper first provides a brief introduction to the IUCM and then summarises five open pit case studies where the IUCM was used for slope stability analysis. The case studies provide a transparent and unbiased record of not only the successful applications, but also cases where the model was not able to accurately replicate the observed behaviour. These examples provide guidelines on where the IUCM can be used successfully, and where pitfalls may occur.
\end{abstract}

Keywords: improved unified constitutive modelling (IUCM), advanced numerical modelling, constitutive model, slope stability analysis, case study, back-analysis, calibration, validation

\section{Introduction to the improved unified constitutive model}

The improved unified constitutive model (IUCM) (Vakili 2016) is a commercially available constitutive model, developed to describe rock masses. This constitutive model is the result of extensive research and development focusing on the rock damage processes and the summation of relevant geomechanics literature. After being validated using several well-documented case histories, it was demonstrated that the IUCM could forecast the extent and severity of damage more accurately than other available constitutive models. As described by Vakili (2016), the majority of the back-analyses and validation studies completed during the development of the IUCM used mining case histories dealing with small to medium sized underground excavations including development, shafts, pillars, and open stopes. While the accuracy of the IUCM has been documented for underground stress conditions, there are limited published accounts of the IUCM's effectiveness for modelling open pit stability. Therefore, use of the IUCM for open pit slope stability assessment requires further validation using open pit case studies. 
The aim of this paper is to give a brief introduction to the IUCM, as well as summarise five open pit case studies where the IUCM was used for slope stability analysis. The case studies aim to provide a transparent and unbiased record of not only the successful applications, but also some known limitations where the IUCM was not able to accurately replicate the observed slope behaviour. These case studies also provide guidelines on how to derive input parameters, where the IUCM can be used successfully, and where pitfalls may occur.

\section{What is the improved unified constitutive model?}

As mentioned previously, the IUCM is a constitutive model, which is a set of rules that dictates how the rock mass within a numerical simulation behaves. The current version of the IUCM has been implemented into Itasca's finite difference code FLAC3D. The IUCM includes particular failure mechanisms and complexities that are typically ignored in commercially available Mohr-Coulomb, bi-linear Mohr-Coulomb or Hoek-Brown constitutive models. The model provides the advantages and model complexities as discussed below.

The model uses a continuous Mohr-Coulomb approximation of the Hoek-Brown failure envelope, instead of the linear or bi-linear approximations that are typically used. Linear approximations of the Hoek-Brown criterion are prone to considerable numerical errors in both high and low stress conditions, depending on how the linearisation is chosen. For open pit applications, the IUCM is able to account for both the lower stress conditions expected in individual benches or crests, as well as the higher stress conditions, responsible for deep-seated failure with a single criterion. The continuous nature of the IUCM provides considerably less conservative simulations compared to linear approximations and provides a more accurate representation of the rock mass strength throughout the entire open pit. As the failure criterion is continuous, the IUCM also tends back to a linear Mohr-Coulomb envelope for the residual state of completely broken and crushed rock.

The model explicitly includes rock strength anisotropy through the use of a nonlinear ubiquitous joint model. This approach accounts for the known directional strength of rock (Jaeger 1960), assigning unique Hoek-Brown failure envelopes to the intact rock, and foliation or plane of weakness separately. The IUCM's approach to anisotropy is in contrast to the conventional approach where the foliation or plane of weakness is defined using a linear Mohr-Coulomb envelope. The non-linear envelope used in the IUCM can potentially provide less-conservative and more-accurate strength estimates in anisotropic rock masses.

The critical plastic strain (i.e. the softening response) in the IUCM is governed by the equations proposed by Lorig \& Varona (2013), derived as part of the international caving study. The inclusion of this plastic strain correction means that the IUCM corrects for some zone dependencies, particularly those associated with the post-peak softening components.

The dilation angle in the IUCM is determined using the relationship proposed by Alejano \& Alonso (2005). Their relationship estimates the current peak dilation angle, as a function of the acting confining stress, internal friction angle and the uniaxial compressive strength. The dependency of dilation on the acting confining stress produces high dilation angles at low confinement, and low dilation angles at high confinement. The dilation angle also softens within the IUCM, ultimately reducing to zero. This dynamic behaviour for dilation is also modelled after the observations in laboratory rock testing.

The IUCM does not have a fixed post-peak model (softening table). All transient post-peak strength parameters are calculated as a function of the acting confining stress and loading history. Confinement dependency is a major factor controlling rock damage; however, it is largely ignored in all other commercially available constitutive models. For low confining stresses, the IUCM replicates a cohesion and friction strain softening response, while at high confining stresses, the IUCM replicates the observed cohesion softening and friction hardening response. This dynamically defined post-peak response allows for progressive failure to occur near the boundary of the excavation and at the same time limits the propagation of damage to unrealistic depths. 
Practitioners generally assume a constant modulus of elasticity (Young's modulus) for the rock mass, irrespective of its damage state. In reality, when rock undergoes failure and continuous loading, more voids are generated within the rock mass. The more porous a rock mass is, the lower its elastic modulus should be. Reductions to the rock mass' modulus of elasticity significantly affect the redistribution of stresses around failed areas, including the induced confining stresses. The impact of modulus softening can be more pronounced in situations where significant rock mass damage or deformation is expected; for example in deep open pit mines. Reyes-Montes et al. (2012) reviewed and collated the previous literature in this area and presented an empirical relationship between modulus drop and the level of porosity in a rock mass. The IUCM uses this relationship to update the elastic modulus values according to changing porosity values.

As a summary, the IUCM aims at collating and accounting for all experimentally and operationally documented rock mass behaviours as a function of the acting stresses and accumulated plastic strain. The levels of accuracy included within the IUCM are substantially more than what the typical practitioner would assume. This increased complexity is intended to better reflect the actual rock mass failure process, with the intent of increasing the reliability and validity of numerical modelling approaches.

The following sections outline some of the current case histories of the IUCM being applied to open pit problems.

\section{$3 \quad$ Improved unified constitutive model case study 1}

Mine1 is a deep base metal open pit, with a depth of approximately $400 \mathrm{~m}$ and a diameter of almost $600 \mathrm{~m}$. Mine1's geotechnical characteristics allow for an overall aggressive slope design, with steep batters, approaching $90^{\circ}$ in walls that have largely favourable structural controls. The mine is developed in rock mass conditions that were expected to be favourable for large-scale slope stability, but a proposed steeper design raised concerns about structurally controlled larger-scale stability that might also be stress-driven. Mine1 is hosted within a north-south striking alteration zone of a regional syncline. The rock types are a sequence of schists that strike north-south with foliation dipping east between $50^{\circ}$ and $70^{\circ}$.

\subsection{Data available and input derivation}

Mine1 has a comprehensive database of rock strength testing and structural mapping, and well-defined geotechnical domains that relate to the rock types, rock mass structure domains, and weathering. The host rocks in the central part of Mine1 are blocky to massive, strong, and have brittle failure characteristics. Extensive foliation plane joints occur in part of the central sequence and are defined by a separate domain. The marginal schists to the west and east are weaker, with more ductile failure characteristics, and are blocky to seamy with lower geological strength index (GSI). A transition zone between the brittle and ductile schists is also defined by a separate geotechnical domain.

The strong rocks at Mine1 mean that structures control pit wall stability. The mine's owner employs numerous rockfall hazard controls and ground support to limit the impacts of structures. One wall in particular is impacted by adversely dipping joints that undercut batters, and ground support is used to retain berm crests. However, the mine's owner recognised the potential for larger-scale complex failure through the rock mass and along these structures, particularly as the pit approached its ultimate depth and mining-induced stresses may have an impact. The aim of numerical modelling at Mine1 was to assess potential complex structurally influenced failure. Therefore, the numerical model included explicit structures generated as a discrete fracture network (DFN), and rock mass between structures represented by IUCM, including the use of anisotropic parameters to represent the foliated weaker and more ductile domains. 
Table 1 presents the methods used to calculate each parameter from the available geotechnical data sets. Overall. the authors consider the quality and quantity of available data as 'high' for this mine.

Table 1 Method of deriving each IUCM parameter for Mine1

\begin{tabular}{ll}
\hline IUCM parameter & Calculation method \\
\hline Density & Median value from laboratory testing \\
Young's modulus & Median value from laboratory testing \\
Matrix uniaxial compressive strength (UCS) & Median value from laboratory testing \\
Matrix Hoek-Brown constant $\left(m_{i}\right)$ & Typical values adopted and ratio of UCS/UTS \\
Foliation Hoek-Brown constant $\left(m_{i}\right)$ & Relationship proposed by Vakili et al. (2014) \\
Anisotropy factor & Guidelines proposed by Vakili et al. (2014) \\
Foliation dip/dip direction & Structural modelling/drilling information \\
Geological strength index (GSI) & Assessed from exposure mapping \\
Residual cohesion & IUCM default used (0 MPa) \\
Residual friction & IUCM default used (45 $)$ \\
Residual uniaxial tensile strength (UTS) & IUCM default used (0 MPa) \\
Strain softening modifier & Softening response dictated by the relationship \\
& proposed by Lorig \& Varona (2013) \\
Groundwater & A drawn-down phreatic surface was used to \\
& represent the groundwater \\
\hline
\end{tabular}

\subsection{Model output}

The validation of the model for Mine1 used the following criteria:

1. Modelled large-scale mine slope displacement correlates well with displacement monitoring gathered by long-term laser scanning.

2. The region of greatest displacement correlates with a convex wall, where confining stresses are lower, and the pit wall is nearer an explicitly modelled structure with the weaker and more ductile geotechnical domain. The mechanism was confirmed to be active-passive displacement with sliding along the structures, tensile yield in the upper slope and shear in the lower slope, and agreed with monitoring observations.

3. The overall pit slope Factor of Safety was lowest in the region of greatest displacement, but in excess of 1.2 , and the pit has remained stable.

Comparisons between the measured slope displacement and the displacement predicted by the model and the captured movement mechanism are shown in Figure 1. More details about this case study are provided in Lucas et al. (2020).

It should be noted that the apparent displacement in Figure $1 \mathrm{a}$ is $x / \sin (\mathrm{a})$ where $\mathrm{x}$ is the displacement perpendicular to the wall, and $a$ is the angle of the line of sight to the wall. Therefore, the displacement in Figure $1 \mathrm{a}$ is greater than the modelled displacement in Figure $1 \mathrm{~b}$. 


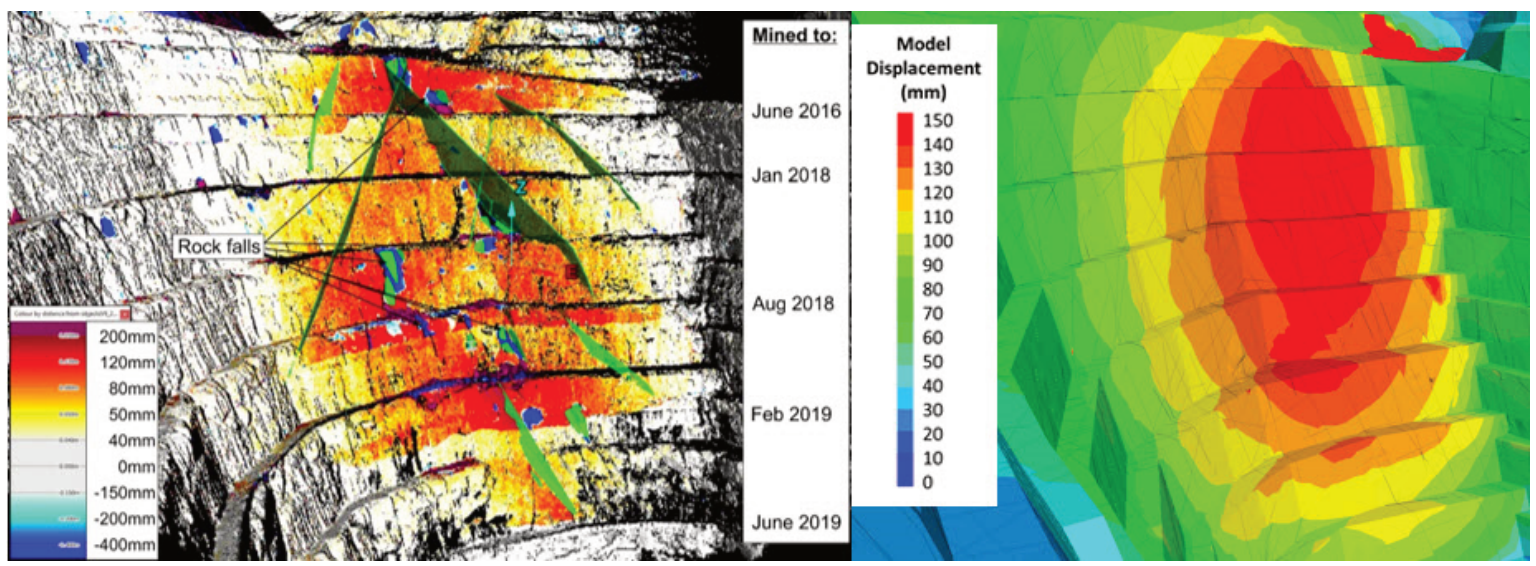

Figure 1 Comparison of (a) monitored (laser) versus (b) modelled displacement for Mine1 (structures are not shown distinctly but were included in the model)

\subsection{Numerical modelling assumptions and limitations}

Structurally controlled failure on explicit structures is limited by the representation of these structures in the model. The DFN generated rock mass structures represented a scaled jointed rock mass, with modelled structures more persistent, and at wider spacing, than those that occur in the mine, but with length, spacing and frequency of each set relative to each other set. Hence, rock mass behaviour at a larger scale will be appropriately represented, although stability at a bench-scale is not expected to be representative. The model predicted crest losses and batter-scale failures on structures but not at locations and scales that represent the mine's experience. This was considered to be reasonable as batter-scale stability was not the focus of the modelling.

The in situ shear strength of large-scale geological structures was represented by the Barton-Bandis criterion, using laser scanned profiles to assess the joint roughness coefficients of the critical structures. This is separate and distinct from IUCM benefits and limitations.

The number and spacing of explicit structures are limited by computing power. The finite difference mesh was conformed to the DFN generated structures, the pit design, and the mining stages, and more closely spaced structures would require a finer mesh. The model for Mine1 tested the limits of available computers. Rock mass between each explicit structure is represented as a homogenised material with joints represented by GSI, and foliation included as an anisotropic representation where applicable. The relative frequency, persistence and spacing of explicit structures were considered to be suitable to represent the structurally controlled rock mass at an overall slope scale.

\section{$4 \quad$ Improved unified constitutive model case study 2}

Mine2 is one of a series of historic base metal pits which have not been mined for decades. Mine2 has had a problematic history, with most slope walls experiencing considerable historic instabilities. The local geology is comprised of primarily weak and weathered sub-vertical metamorphic schistose and mafic units.

\subsection{Data available and input derivation}

Mine2 was notable for its comparatively poor geotechnical database. Mine2 had limited and erroneous core logging data, and much of the data was discarded due to inconclusive accuracy. Laboratory testing, if available, included uniaxial compressive tests, Brazilian tests, single and three stage triaxial tests and direct shear tests. The number of tests available for each major lithology unit was often zero, with many lithologies having fewer than five samples. Using the available data, Table 2 lists the methodology used to derive the IUCM material parameters for each lithology. Overall, the quantity of available data is considered 'low' for this mine and quality is considered 'medium'. 
Table 2 Method of deriving each IUCM parameter for Mine2

\begin{tabular}{ll}
\hline IUCM parameter & Calculation method \\
\hline Density & Median value from laboratory testing \\
Young's modulus & Median value from laboratory testing \\
Matrix uniaxial compressive strength (UCS) & Mode value from field and laboratory tests \\
Matrix Hoek-Brown constant $\left(m_{i}\right)$ & $\begin{array}{l}\text { Curve fitting using Brazilian, uniaxial and triaxial } \\
\text { testing data }\end{array}$ \\
Foliation Hoek-Brown constant $\left(m_{i}\right)$ & Relationship proposed by Vakili et al. (2014) \\
Anisotropy factor & $\begin{array}{l}\text { Ratio of matrix to foliation UCS values using the } \\
\text { mode value }\end{array}$ \\
Foliation dip/dip direction & Obtained from structural drilling \\
Geological strength index (GSI) & $\begin{array}{l}\text { Weighted mean used. Calculated using the } \\
\text { relationship between GSI and rock mass rating }\end{array}$ \\
Residual cohesion & IUCM default used (0 MPa) \\
Residual friction & IUCM default used (45 $)$ \\
Residual uniaxial tensile strength (UTS) & IUCM default used (0 MPa) \\
Strain softening modifier & $\begin{array}{l}\text { Softening response dictated by the relationship } \\
\text { proposed by Lorig \& Varona (2013) }\end{array}$ \\
Groundwater & $\begin{array}{l}\text { A drawn-down phreatic surface was used to } \\
\text { represent the groundwater }\end{array}$ \\
\hline
\end{tabular}

Due to the limited number of samples available for each lithology, it was initially anticipated that significant calibrations were required to meet the output criteria detailed below. Lithologies which had insufficient data were generally assigned conservative estimates from the literature.

\subsection{Model output}

The validation of the IUCM for Mine2 used the following criteria:

1. Simulate the slow-moving mechanism and crest tensile cracking for the northeastern wall, indicated by the velocity based criterion derived by Lorig \& Varona (2000).

2. Simulate the slumping and kinematic failure for the west wall.

3. Simulate the large-scale wedge failure of the east wall.

In order to replicate the conditions of the northeastern wall, no adjustments to the initial material parameters were needed, and the observed slow-moving failure mechanism was replicated reasonably accurate. For the western wall instability, the material parameters for the weathered units were increased to obtain the observed failure size as the model showed excessive failure (Figure 2). 


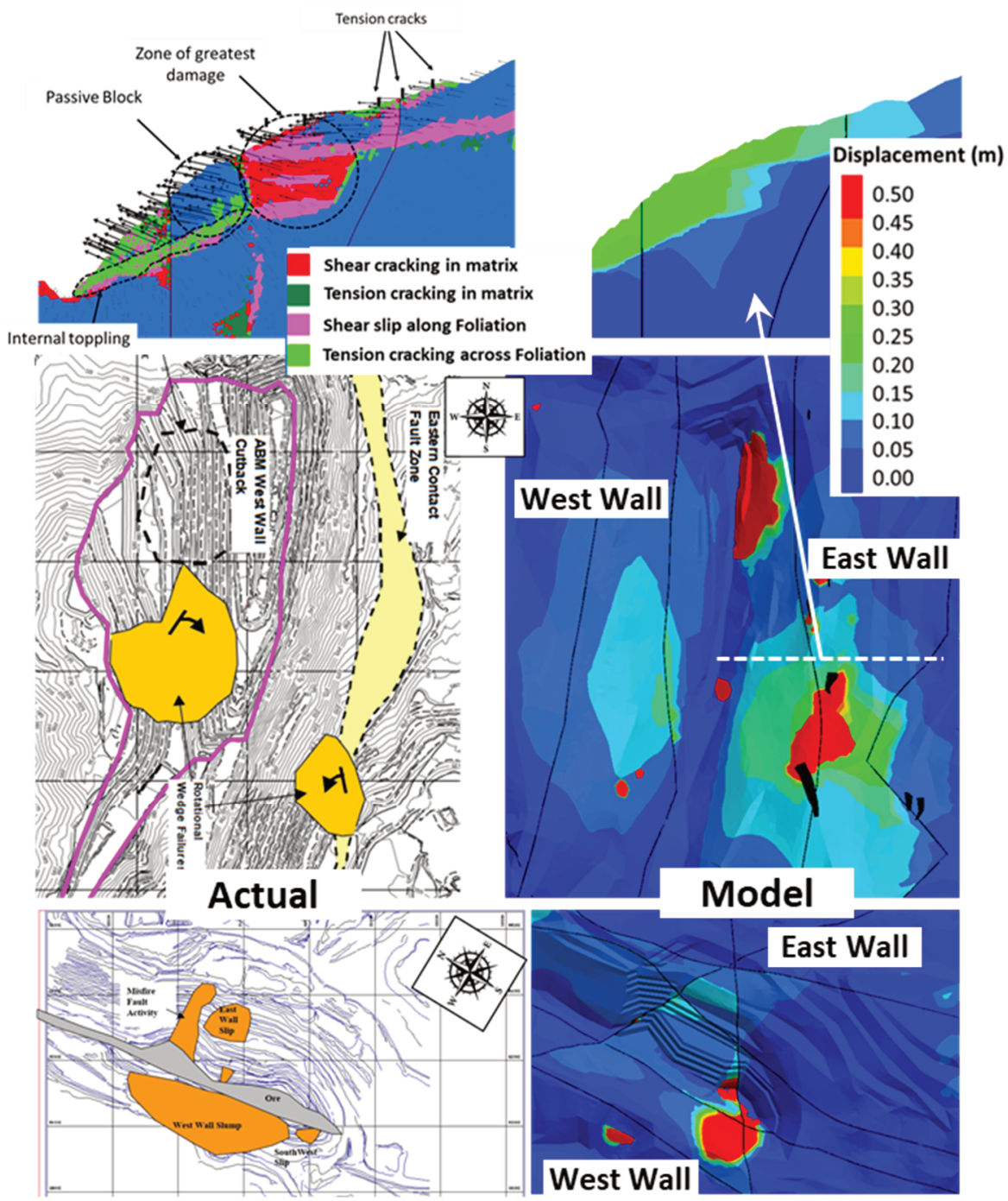

Figure 2 Top is northeast wall slow-moving failure mechanism, middle is plan view of northeastern and west wall failures, and bottom is a plan view of southeast and west wall failures

The model was unable to replicate a large-scale slump failure in the eastern wall, unless the rock mass and fault properties were downgraded to unrealistically low values (bottom images in Figure 2). However, this slump failure was also poorly documented, with a considerable amount of uncertainty as to the actual mining conditions prior to and during failure. The main conclusion of the inability to replicate the eastern wall failure was that the conditions and structural geometry were insufficiently known to replicate the failure. The model also predicted a failed slope in the upper most northeast corner which did not occur in reality.

\subsection{Numerical modelling assumptions and limitations}

The structurally controlled failure was not sufficiently replicated. It was noted that the inability to replicate this failure was attributed to the poor understanding of the structure's geometry and position. The IUCM is known to be limited in applications that deal with strictly large-scale structural failures, unless the controlling structures are included explicitly and correctly.

Material parameters for some areas needed to be iteratively adjusted prior to replicating the observed failures accurately. This is largely attributed to limited geotechnical data. 


\section{$5 \quad$ Improved unified constitutive model case study 3}

Mine3 is an operating, $600 \mathrm{~m}$ deep gold mine. Ongoing studies concerning Mine3 have proposed multiple cutbacks, moving the final pit geometry close to $1,000 \mathrm{~m}$ deep. The current stable slope design criterion has inter-ramp slope angles of between $40^{\circ}$ and $55^{\circ}$, batter angles between $60^{\circ}$ and $75^{\circ}$, and final bench heights of between 20 and $30 \mathrm{~m}$. The regional geology for Mine3 is comprised of primarily folded metamorphosed metasediments, and igneous rocks.

\subsection{Data available and input derivation}

Mine3 was commendable for its substantial amount of field and laboratory testing data. Mine3 had extensive anisotropic testing data, including tensile and compressive strength in orientations perpendicular and parallel to the major foliation plane. Mine3's database was lacking in samples tested at oblique orientations, as well as triaxial strength testing. Spatially varied strength and rock mass classifications were available and stored within the mine's geotechnical block model. This geotechnical block model included several geotechnical characteristics, including the orientation of the local foliation in terms of dip and dip direction, the intact rock UCS, local geological strength index (GSI) and local rock mass rating (RMR). However, it should be noted that material parameters and laboratory testing were not carried out according to guidelines provided for the IUCM. Table 3 presents the methods used to calculate each parameter from the available geotechnical data sets. Overall, the quantity of available data for this mine is considered 'very high'; however, the authors did not derive the key input parameters from the raw testing and drillhole information and had to rely on previously derived material parameters. Therefore, the quality of the raw data was considered 'unknown'.

Table 3 Method of deriving each IUCM parameters for Mine3

\begin{tabular}{|c|c|}
\hline IUCM parameter & Calculation method \\
\hline Density & Median value from laboratory testing \\
\hline Young's modulus & $\begin{array}{l}\text { 35th percentile was used. This percentile was used to } \\
\text { align with the published correlations between UCS and } \\
\text { Young's modulus (Kumar et al. 2017) }\end{array}$ \\
\hline Matrix uniaxial compressive strength (UCS) & $\begin{array}{l}\text { Supplied geotechnical block model used. When the block } \\
\text { model did not include areas of the model, the } \\
\text { 35th percentile of the laboratory data was used }\end{array}$ \\
\hline Matrix Hoek-Brown constant $\left(m_{i}\right)$ & $\begin{array}{l}\text { Relationship proposed by Hoek \& Brown (2019). The } \\
\text { median value was used to calculate the ratio }\end{array}$ \\
\hline Foliation Hoek-Brown constant $\left(m_{i}\right)$ & Relationship proposed by Vakili et al. (2014) \\
\hline Anisotropy factor & $\begin{array}{l}\text { The foliation Hoek-Brown constant was used in } \\
\text { conjunction with the foliation uniaxial tensile strength to } \\
\text { back calculate the foliation compressive strength }\end{array}$ \\
\hline Foliation dip/dip direction & Supplied geotechnical block model used \\
\hline Geological strength index (GSI) & Supplied geotechnical block model used \\
\hline Residual cohesion & IUCM default used (0 MPa) \\
\hline Residual friction & IUCM default used $\left(45^{\circ}\right)$ \\
\hline Residual uniaxial tensile strength (UTS) & IUCM default used (0 MPa) \\
\hline Strain softening modifier & $\begin{array}{l}\text { Softening response dictated by the relationship proposed } \\
\text { by Lorig \& Varona (2013) }\end{array}$ \\
\hline Groundwater & $\begin{array}{l}\text { A pore pressure grid as output from a hydrogeological } \\
\text { model was used }\end{array}$ \\
\hline
\end{tabular}


The median value was used for Mine3's intact material parameter calculations as the median is a better estimate of central tendency for skewed data. This approach was favoured as higher errors were expected if calculations involving the mean, or some specific percentile was used. This approach was used when calculating parameters which are ratios, for example the Hoek-Brown constant and the anisotropy factor.

\subsection{Model output}

The validation of the IUCM for Mine3 used the following criteria:

1. Simulated rock mass damage had to correlate with historical rockfall data.

2. Match prism data locations and magnitudes with reasonable levels of correlation.

3. Predict the multi-bench failure that occurred.

4. Predict stable slope conditions in all other areas.

During the calibration process for Mine3, five different calibration models were simulated. Each calibration model was modified based on the local geological interpretation, particularly in the region of the multi-bench failure. During the calibration process, only the UCS of one lithology was downgraded. This value was changed based on geological interpretation only, with no other IUCM inputs changing as part of this process. During calibration, several discrepancies were noted between the available datasets, photos of the multi-bench failure and external consultant reports. This supporting information gave initial doubt if the multi-bench failure (Criteria Item 3) would be replicated.

From the initial simulation, the IUCM produced the correlations with prism monitoring displacements as shown in Figure 3. The model showed displacements in a comparable order of magnitude with the prism data. The displacement plot shows the differential displacement for similar duration as the prism monitoring data. It should also be noted that prism displacements are measured from line-of-site.
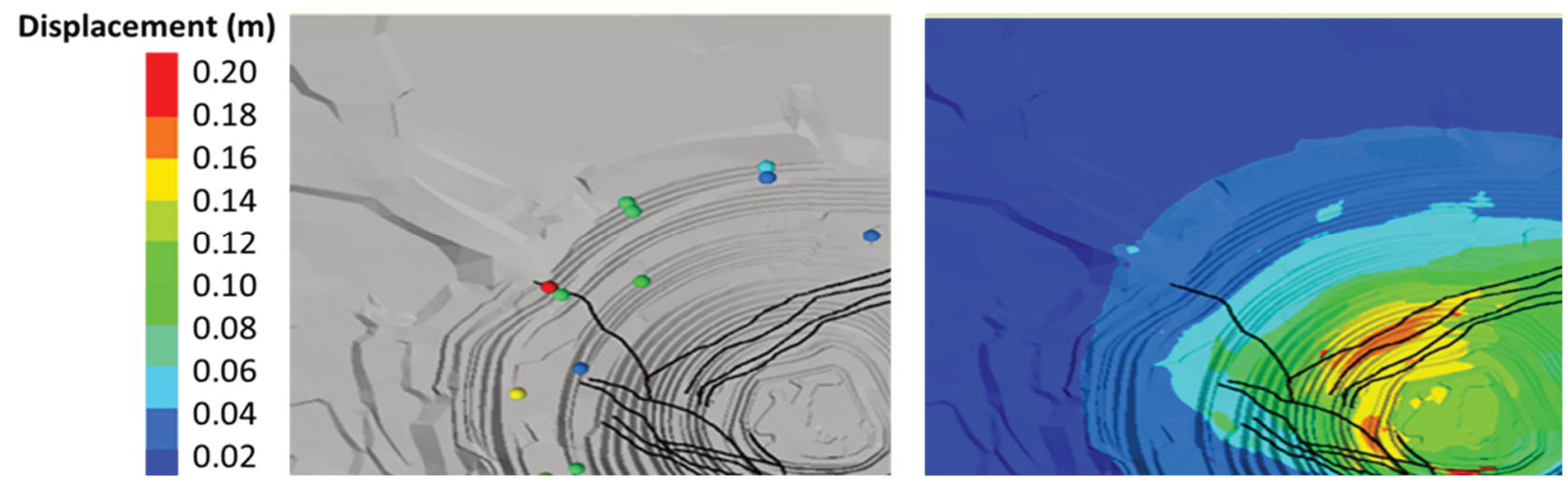

Figure 3 Simulated displacement versus actual displacement

The largest discrepancy between observation and simulation was related to the unusually high GSI values within the geotechnical block model. As the remaining sections of the model matched well, this discrepancy implies potentially erroneous mapping data or misinterpreted geology.

The location of rockfalls, shown in Figure 4 corresponded moderately well to the simulated volumetric strain. Due to the coarseness of the discretisation scale, the correlation with volumetric strain was much lower than usual (approximately $0.15 \%$ volumetric strain) compared to the typical 3 to $5 \%$ volumetric strain. This discrepancy in volumetric strain is believed to be a function of the zone discretisation and the size of the reported rockfalls. The IUCM also overestimated the extent of rockfall prone areas compared to the historic rockfall data. 


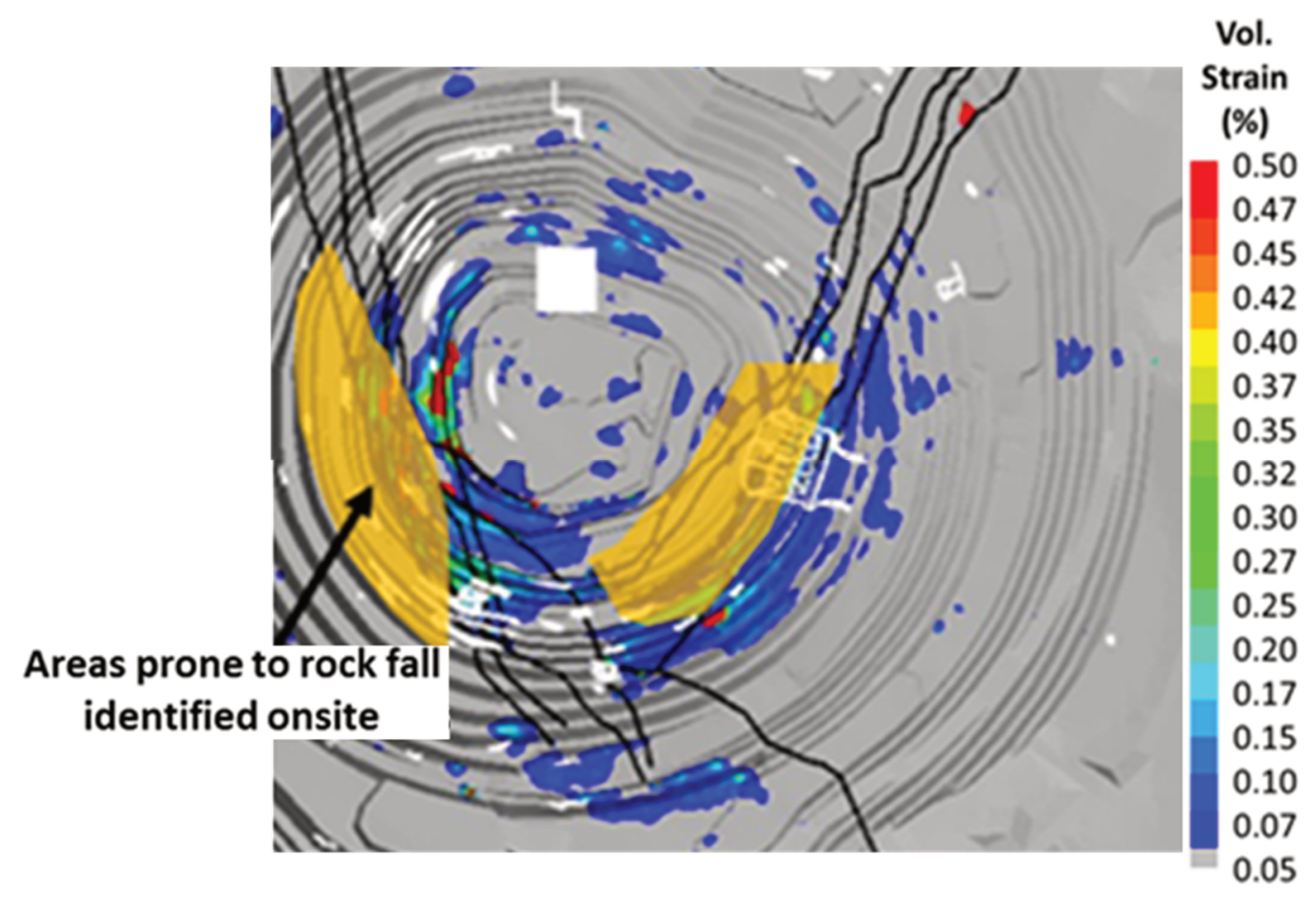

Figure 4 Fall of grounds versus volumetric strain

The simulation of Mine3's multi-bench failure showed increased volumetric strain (see Figure 3) near the failure area, but there were no distinguishing features separating it from nearby sections of the model. As mentioned previously, there was initial doubt that the failure would be able to be replicated using the available data and included structural details. Based on supporting documentation, the failure was described as 'complex', and was caused by a combination of toppling and sliding. Such kinematic styles of failure are not well represented in continuum-based analysis. However, instead it is expected that volumetric strain (or dilatational strain) can highlight the areas that are prone to dilation and confinement reduction and therefore if the unfavourable structural orientation also exists, a bench-scale failure will be imminent. So, the volumetric strain criterion and increased displacement areas can only be indicative of regions that have higher risks of rockfall.

\subsection{Numerical modelling assumptions and limitations}

The structurally controlled failure was not sufficiently replicated. As mentioned previously, the authors of this paper did not expect the failure would be able to be replicated using the IUCM. Local structurally controlled failure is a known limitation of the IUCM unless structures are included explicitly.

Rockfall potential was reasonably well predicted, however the volumetric strain threshold was smaller than anticipated. As mentioned previously, this is believed to be a function of the zone size and the inability to correct for zone size dependencies, particularly in relation to strains. The simulation was also observed to overpredict the failure extent.

\section{Improved unified constitutive model case study 4}

Mine4 is a gold mine comprised of two pits, with the deepest being $300 \mathrm{~m}$. The overall slope angles of the pits are between 35 and 45 degrees, with individual bench configurations having a batter angle of between 60 to 75 degrees. Plans exist to combine the two pits into one big pit, with a maximum depth approaching $700 \mathrm{~m}$. The regional geology is typically moderately dipping (45 to 60 degrees) metamorphosed micaceous schists and metasediments. The regional geology is typically layered, with a significant number of major structures. Mine geologists have identified more than 30 significant structures within the local area. 


\subsection{Data available and input derivation}

Mine4 had a substantial amount of field and laboratory testing data. Mine4 had extensive anisotropic testing, considering the tensile and compressive strength over various orientations with respect to the major foliation. Mine4's geotechnical databases were noted to be lacking in triaxial testing. A geotechnical block model was available for Mine4 which included the local GSI and UCS. Table 4 presents the methods used to calculate each parameter from the available geotechnical data sets. Overall the quantity of available data for this mine is considered 'very high', however authors did not derive the key input parameters from the raw testing and drillhole information and had to rely on previously derived material parameters. Therefore the quality of the raw data was considered 'unknown'.

Table 4 Method of deriving each IUCM parameter for Mine4

\begin{tabular}{|c|c|}
\hline IUCM parameter & Calculation method \\
\hline Density & Median value from laboratory testing \\
\hline Young's modulus & $\begin{array}{l}\text { 35th percentile was used. This percentile was } \\
\text { used to align with the published correlations } \\
\text { between UCS and Young's modulus (Kumar et al. } \\
\text { 2017) }\end{array}$ \\
\hline Matrix uniaxial compressive strength (UCS) & $\begin{array}{l}\text { Obtained from beta angle strength } \\
\text { measurements. The } 35 \text { th percentile was used }\end{array}$ \\
\hline Matrix Hoek-Brown constant $\left(m_{i}\right)$ & Relationship proposed by Hoek \& Brown (2019) \\
\hline Foliation Hoek-Brown constant $\left(m_{i}\right)$ & Relationship proposed by Hoek \& Brown (2019) \\
\hline Anisotropy factor & $\begin{array}{l}\text { Calculated using the minimum and maximum UCS } \\
\text { values and beta angle measurements }\end{array}$ \\
\hline Foliation dip/dip direction & $\begin{array}{l}\text { Locally calculated (interpolated) using the } \\
\text { orientation of lithology contacts }\end{array}$ \\
\hline Geological strength index (GSI) & Supplied geotechnical block model used \\
\hline Residual cohesion & IUCM default used (0 MPa) \\
\hline Residual friction & IUCM default used $\left(45^{\circ}\right)$ \\
\hline Residual uniaxial tensile strength (UTS) & IUCM default used (0 MPa) \\
\hline Strain softening modifier & $\begin{array}{l}\text { Softening response dictated by the relationship } \\
\text { proposed by Lorig \& Varona (2013) }\end{array}$ \\
\hline Groundwater & $\begin{array}{l}\text { A drawn-down phreatic surface was used to } \\
\text { represent the groundwater }\end{array}$ \\
\hline
\end{tabular}

\subsection{Model output}

The validation of the IUCM for Mine4 used the following criteria:

1. Predict the multi-bench failure that occurred in the footwall; the failure mechanism here was complex and it was a combination of initial sliding along the fault following by large-scale sliding along the foliation plane.

2. Simulated rock mass damage had to correlate with historic rockfall data.

3. Predict stable slope conditions in all other areas. 
From the initial simulations and without any adjustment to material parameters, the model was able to produce good correlation between the multi-bench failure in the footwall and model displacement, velocity and volumetric strain (Figures 5 and 6 ). It should be re-iterated that no material properties were altered to get a better match for the footwall (FW) failures.

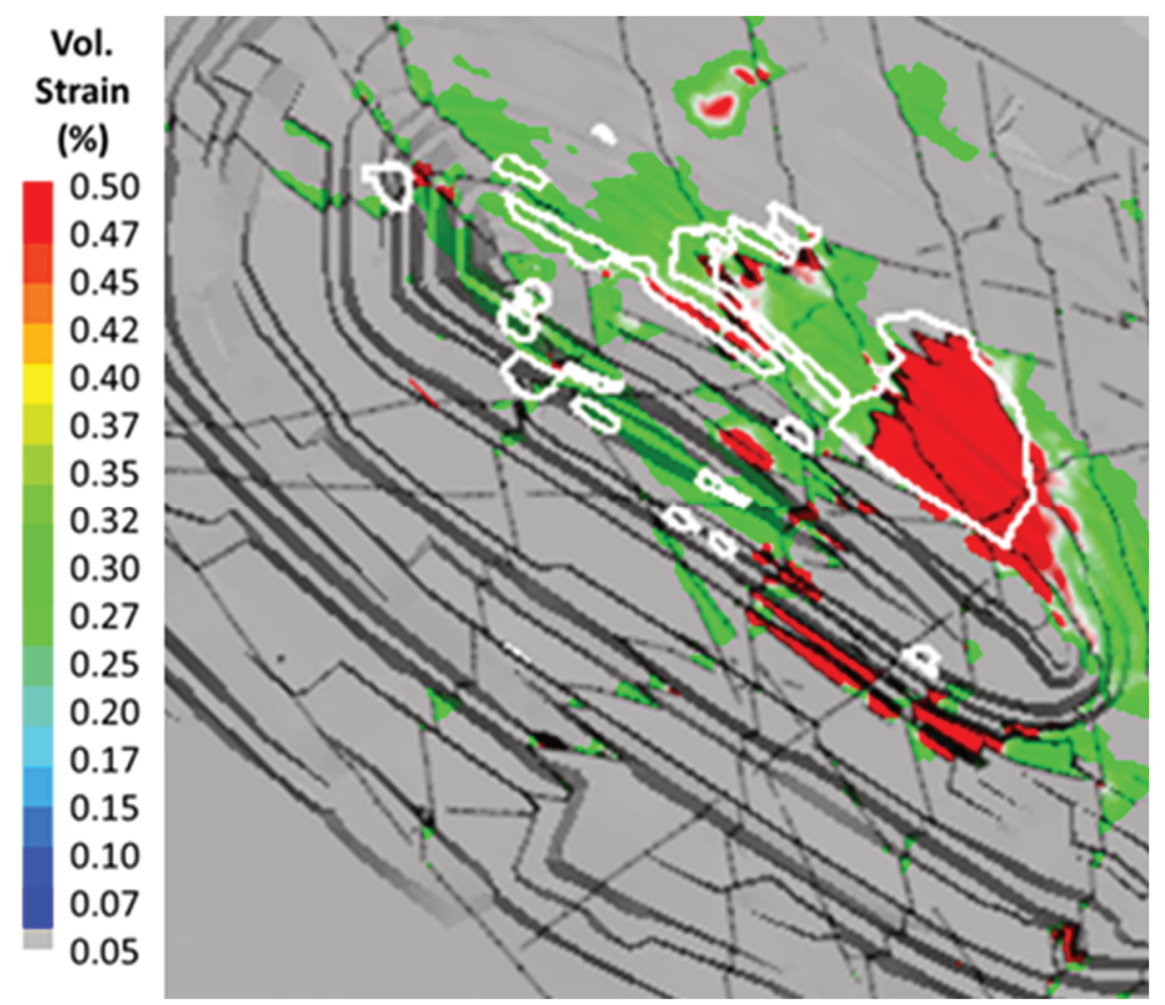

Figure 5 Comparison of volumetric strain and rockfall data (white lines are the mapped rockfall and damaged zones)

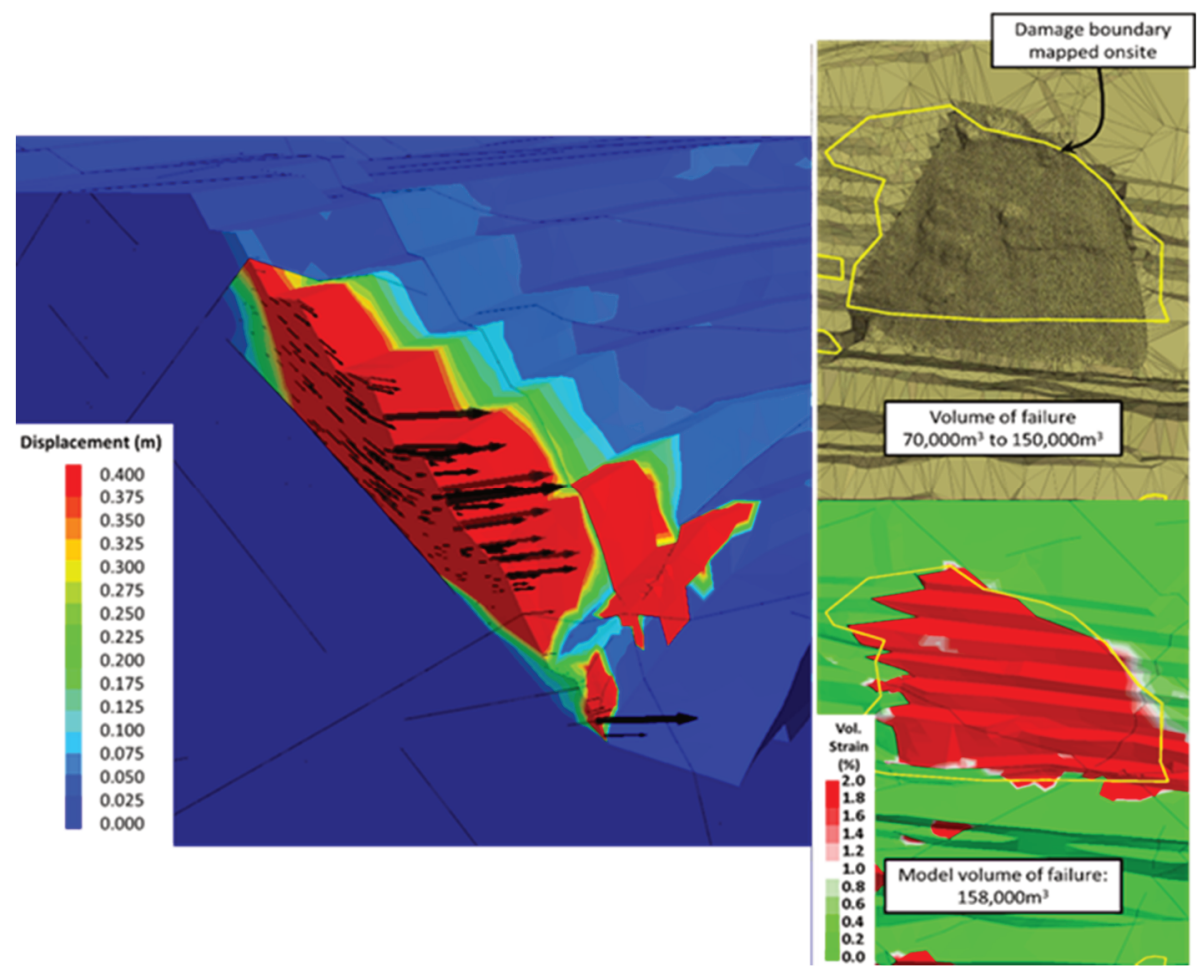

Figure 6 Comparison of volumetric strain and multi-bench failure in the footwall 
For the deep-seated and multi-bench failures, the volumetric strain limit of $2 \%$ correlates well with the failed areas. This is in line with observations presented for underground mines presented by Vakili et al. (2014). For the smaller bench-scale failure areas, the volumetric strain threshold was smaller (around $0.3 \%$ ). As mentioned previously, this is believed to be a function of the zone size and the inability to correct for zone size dependencies, particularly in relation to strains.

The largest discrepancy between observation and simulation was related to some small-scale failure predicted in the hanging wall (HW), which were not observed in reality. This was found to be associated with unrealistically low GSI values in the block model which did not match the GSI mapping of the pit. Once the GSI values were updated to match the mapped GSIs better, much better correlation with rockfall data was obtained (Figure 5). It should be noted that the rockfalls observed in the HW of the northern pit were not included in the model geometry and therefore were not captured.

For this mine, a sensitivity analysis showed that using an isotropic material response could not replicate the FW failure mechanism even when all the faults were included. In addition, an anisotropic model using the conventional ubiquitous joints model (available in FLAC3D) resulted in excessive failure of the entire FW. THe authors believe that two factors lead to inaccuracy of conventional ubiquitous joints model; first, application of linear Mohr-Coulomb criterion for the ubiquitous joints (IUCM employs Hoek-Brown for the weakness plane as well) and secondly, assigning the joint defect strength (obtained from shear-box testing) to the ubiquitous joints. The linear criterion is not able to account for continuous changes of confinement in more complex conditions and also assigning defect strength to the ubiquitous joints for the entire rock mass is a very conservative assumption.

\subsection{Numerical modelling assumptions and limitations}

While the correlation between model and observations was surprisingly good, in particular for replicating the failure mechanism on the footwall, it was noted that there were considerable uncertainties with the derived GSI values and the fault properties.

It was realised later that even with a GSI increase of 10 , the failures were still replicated reasonably well. This helped to target future data collection locations to realise future optimisation and slope steepening benefits.

\section{$7 \quad$ Improved unified constitutive model case study 5}

\subsection{Mine background}

Mine5 is a moderately deep $(<400 \mathrm{~m})$ base metals mine. The regional geology is generally described as moderately competent, and is predominantly comprised of layered metamorphic units, with some igneous intrusions. The orebody and regional geology are moderate to steeply dipping, with the HW and FW dipping $75^{\circ}$ and $65^{\circ}$ respectively. The orebody is characterised by a parallel orientated shear zone, with several major faults also being modelled perpendicular (to the orebody) in the HW. The RMR for the host rock is between 45 and 60 . Intact UCS would be moderate and is typically greater than 50 , but less than $100 \mathrm{MPa}$.

\subsection{Data available and input derivation}

For Mine5, model inputs were determined through several years of engagement with the site and reviewing information relating to laboratory testing and rock mass characterisation. There were also several underground and open pit back-analysis studies done in the past which were used to assist with deriving the material parameters. Overall, the quality and quantity of the available data for this mine are considered 'medium'. 
Table 5 presents the methods used to calculate each parameter from the available geotechnical data sets.

Table 5 Method of deriving each IUCM parameter for Mine5

\begin{tabular}{ll}
\hline IUCM parameter & Calculation method \\
\hline Density & Median value from laboratory testing \\
Young's modulus & Average from laboratory testing \\
Matrix uniaxial compressive strength (UCS) & Average from laboratory testing \\
Matrix Hoek-Brown constant $\left(m_{i}\right)$ & From limited triaxial testing \\
Foliation Hoek-Brown constant $\left(m_{i}\right)$ & Relationship proposed by Vakili et al. (2014) \\
Anisotropy factor & $\begin{array}{l}\text { Estimated from reviewing the lab testing data but } \\
\text { without test certificates or reviewing the samples }\end{array}$ \\
Foliation dip/dip direction & From pit mapping \\
Geological strength index (GSI) & $\begin{array}{l}\text { Provided by site personnel from historical } \\
\text { mapping }\end{array}$ \\
Residual cohesion & IUCM default used (0 MPa) \\
Residual friction & IUCM default used (45 $)$ \\
Residual uniaxial tensile strength (UTS) & IUCM default used (0 MPa) \\
Strain softening modifier & $\begin{array}{l}\text { Softening response dictated by the relationship } \\
\text { proposed by Lorig \& Varona (2013) }\end{array}$ \\
Groundwater & A drawn-down phreatic surface was used to \\
represent the groundwater
\end{tabular}

\subsection{Improved unified constitutive model output}

The validation of the IUCM for Mine5 used the following criteria:

1. Match inclinometer data locations and magnitudes with reasonable levels of correlation.

2. Replicate a multi-bench failure.

3. Predict stable slope conditions in all other areas.

The main validation case study for the IUCM was completed over a two-year period. During this period, inclinometer and slope monitoring systems quantified the displacement of the FW. Also occurring during this time was a surficial $40 \mathrm{~m}$ high, multi-bench slope failure in the HW. Based on the local geometry, this single analysis considered the two common slope failure mechanisms (i.e. sliding and toppling) configurations.

Initial simulations produced some fault related deep-seated failure in some sections of the HW which was not observed. The strength of the faults was subsequently increased to prevent failure from initiating. No other material parameters required modification to replicate the observed response. The IUCM was able to replicate the observed failure mechanism in the HW. Comparisons are shown in Figure 7. 


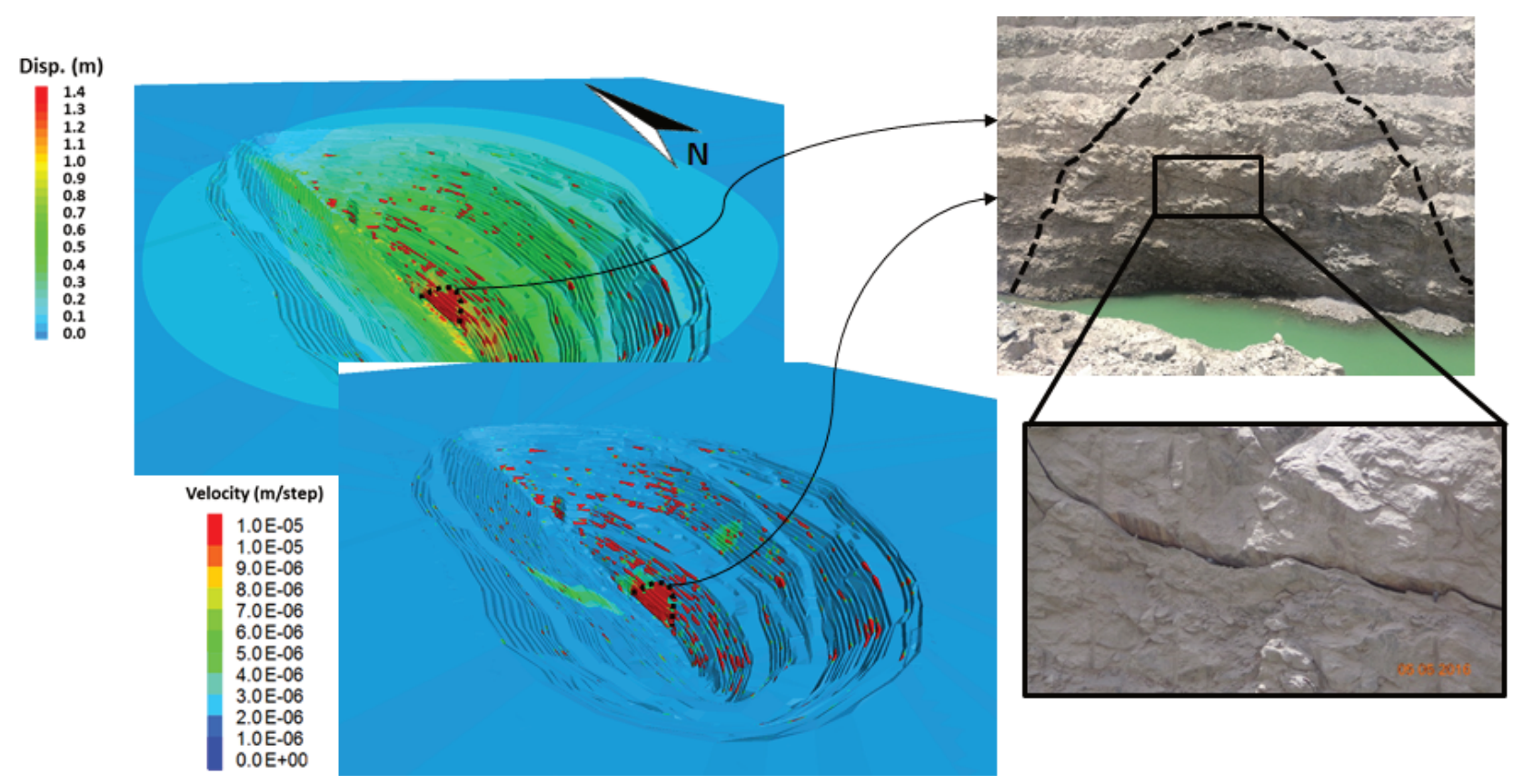

Figure 7 Comparisons between IUCM simulation and actual failure

Displacements predicted in the footwall were in general agreement with monitoring data. The back-analysis of Mine5 did not have any significant deep-seated rock mass failure. Without a sufficiently large historic failure, it is not possible to fully verify the rock mass response.

\subsection{Numerical modelling assumptions and limitations}

The IUCM was unable to be fully verified as there were only small-scale calibration failure cases. No large-scale failure occurred to date for comparison.

Stability calculations involving creep mechanisms are not currently adequately addressed in numerical models. While the IUCM can identify areas that are prone to slow progressive movement, it is unable to describe this motion completely in terms of actual time.

Fault parameters were not representative as fault related failure was overpredicted.

\section{Conclusion}

This paper has presented a brief overview of the IUCM and summarises five open pit case studies where the IUCM was used for slope stability analysis. These case studies provided a transparent and unbiased record of the strengths and weaknesses when applied to open pit analysis. These examples also provided guidelines on how to derive input parameters. The following strengths were identified from these case studies when using IUCM:

1. General purpose application. There are a wide range of rock types, lithologies and weathering included in these simulations.

2. Relatively easy inputs to derive.

3. Anisotropic aspects can be included.

4. Higher risk of rockfalls can be identified from simulations.

5. Major failures can be predicted with a reasonable level of accuracy, even when the quality and quantity of data is poor.

6. Pit slope displacement areas are quantifiable with reasonable accuracy. 
As mentioned previously, the IUCM has some known limitations which are actively being researched to provide improved reliability. The following limitations and learnings should be considered when using IUCM for pit slope stability analysis:

1. Large structures other than foliation/bedding/schistosity should be included explicitly.

2. At this stage, volumetric strain outputs require calibration as mine-scale pit models do not include meshing of sufficient resolution to resolve accurate volumetric strain prediction.

3. Rockfall areas can only be identified as zones with potential for higher risk of rockfall as these regions lack confinement. The final trigger that initiates many rockfalls is unfavourable joint orientations and positions which cannot be predicted with continuum approach.

4. Stability calculations involving creep mechanisms are not adequately addressed at current. While the IUCM can identify areas that are prone to slow progressive movement using the model velocity, it is unable to describe this motion in detail.

\section{References}

Alejano, LR \& Alonso, E 2005, 'Considerations of the dilatancy angle in rocks and rock masses', International Journal of Rock Mechanics and Mining Sciences, vol. 42, no. 4, pp. 481-507.

Hoek, E \& Brown ET 2019, 'The Hoek-Brown failure criterion and GSI - 2018 edition', Journal of Rock Mechanics and Geotechnical Engineering, vol. 11, no. 3, pp. 445-463.

Jaeger, JC 1960, 'Shear failure of anisotropic rock', Geological Magazine, vol. 97, no. 1, pp. 65-72.

Kumar, R, Bhargava, K \& Choudhury, D 2017, 'Correlations of uniaxial compressive strength of rock mass with conventional strength properties through random number generation', International Journal of Geomechanics, vol. 17, no. 2, pp. 1-9.

Lorig, L \& Varona, P 2000, 'Practical slope stability using finite difference codes', in WA Hustrulid, MK McCarter \& DJA Van Zyl (eds), Proceedings of Slope Stability in Surface Mining, Society for Mining, Metallurgy, and Exploration, Englewood.

Lorig, L \& Varona P 2013, 'Guidelines for numerical modelling of rock support for mines', in Y Potvin \& B Brady (eds), Proceedings of the Seventh International Symposium on Ground Support in Mining and Underground Construction, Australian Centre for Geomechanics, Perth, pp. 81-105.

Lucas, D, Vakili, A \& Hutchison, BJ 2020, 'Three-dimensional numerical modelling for successful design of steep slopes at the Kanmantoo copper mine', in PM Dight (ed.), Proceedings of the 2020 International Symposium on Slope Stability in Open Pit Mining and Civil Engineering, Australian Centre for Geomechanics, Perth, pp. 1083-1096.

Reyes-Montes, JM, Sainsbury, B, Andrews, JR \& Young, RP 2012, 'Application of cave-scale rock degradation models in the imaging of the seismogenic zone', Proceedings of the Sixth International Conference and Exhibition on Mass Mining, Canadian Institute of Mining, Metallurgy and Petroleum, Westmount.

Vakili, A, Albrecht, J \& Sandy, M 2014, 'Rock strength anisotropy and its importance in underground geotechnical design', Proceedings of AUSROCK 2014: Third Australasian Ground Control in Mining Conference, Australasian Institute of Mining and Metallurgy, Carlton.

Vakili, A 2016, 'An improved unified constituitive model for rock material and guidelines for its application in numerical modelling', Computers and Geotechnics, vol. 80, pp. 261-282.

Vakili, A 2017, 'The improved unified constitutive model: a fine-tuned material model tailored for more challenging geotechnical conditions', in J Wesseloo (ed.), Proceedings of the Eighth International Conference on Deep and High Stress Mining, Australian Centre for Geomechanics, Perth, pp. 387-400, https://doi.org/10.36487/ACG_rep/1704_27_Vakili 